\title{
Electrical Safety Earthing
}

\author{
Rohan Panchal ${ }^{1}$ \\ ${ }^{1}$ B.Tech Electrical Engineering \\ Indus University, Ahmedabad. \\ Gujarat, India.
}

\begin{abstract}
This paper is aimed at developing a conventional procedure of electrical earthing and creating a safety measure against various kinds of faults than can be fatal for a man. It consists of mainly () sections. The first being the introduction to the process of transferring the charge immediately to the ground using a low resistance wire, the need for electrical earthing in various places. Secondly, I have mentioned the type of various earthing methods. Further, I have discussed about the importance of earthing and lastly I have discussed in detail about the classification of earthing systems.
\end{abstract}

Keyword:- Electrical Safety Earthing, Grounding, Neutral earthing,

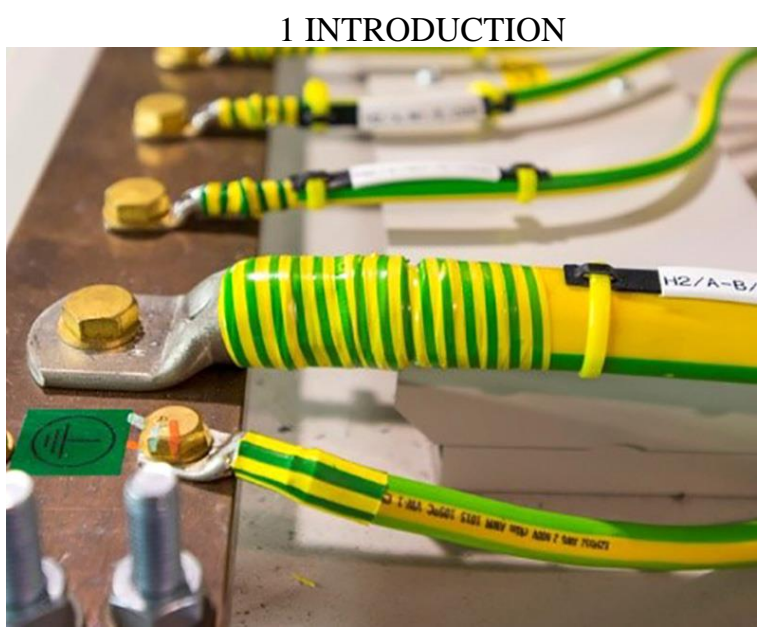

The process of transferring the immediate discharge of electrical energy to the ground using a low resistance wire is known as electrical grounding. Electrical grounding is accomplished by attaching the ground to the nonconductive part of the equipment or the neutral of the power system.

Installation of each building, equipment, power plant, substation involved in electricity requires grounding directly or through a grounding system. The main purpose of earthing in electrical networks is security.

But when the neutral of a system is not connected to the earth, it will be known as an electrical system without the meaning shown in Fig. 1.

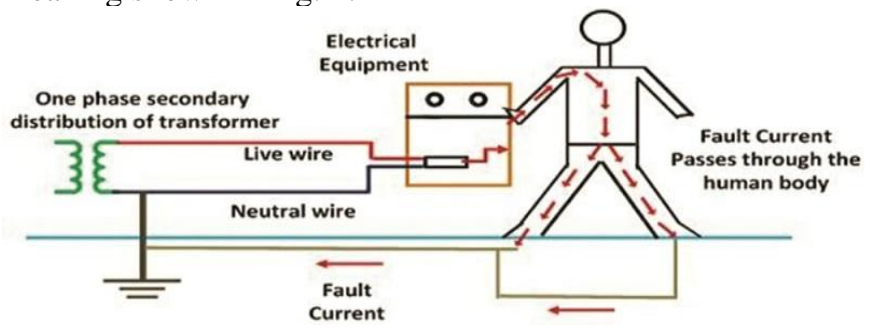

Figure 1: Electrical system without earthing

\author{
Kaushal Patel ${ }^{2}$ \\ ${ }^{2}$ Asst. Professor \\ Indus University, Ahmedabad. \\ Gujarat, India.
}

Above all, galvanized iron is used for grounding.. The earthing provides the simple path to the leakage current and fault current in the system. Above all, galvanized iron is used for grounding. The earthing provides the simple path to the leakage current and fault current in the system. The short-circuit current of the equipment passes to the earth which is assumed to have zero potential. This protects system equipment and personnel working with it from damage and electric shock, as shown in Figure 2: Electrical system with earthing

Grounding is unlikely to reduce the total amplitude of the overvoltage produced by switching power or overvoltage, but it can, however, reduce the possibility of excessive voltage at phase-to-earth isolation of a particular phase.

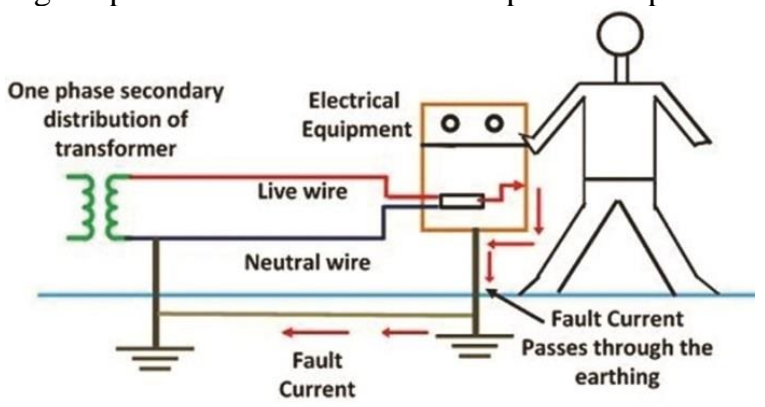

The earth resistance of the system should be such that in the event of a fault against which earthing is designed to provide protection, protective equipment shall operate to make the main or faulty installation safe. In most cases, such operation involves disassembling the main or faulty installation, for example by circuit breakers or fuses.

\section{TYPES OF ELECTRICAL EARTHING}

Electrical equipment mainly consists of two nonconductive parts. These parts are neutral for electrical equipment systems or chassis or support structures. By the earthing of these two non-conductive parts of the electrical system, earthing can be classified into two types: neutral earthing and equipment earthing.

Neutral Earthing

In neutral earth, the system conductor neutral is directly connected to the earth using a metal conductor wire. Neutral grounding is also known as system grounding. This type of grounding is mainly provided to the star winding system. For example, generators, transformers, motors, etc. are provided in the generator ground, as shown in Figure 3 


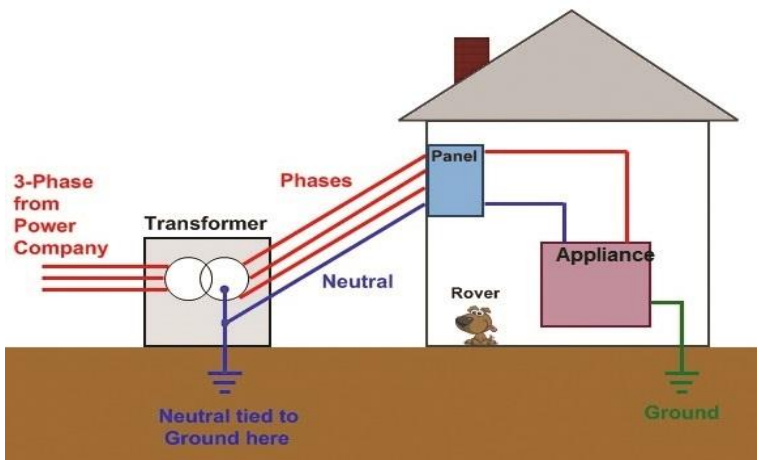

Figure 3: Neutral and equipment earthing

Equipment Earthing

This type of grounding is provided to the electrical equipment. The non-current-carrying part of the device, such as a metal frame, is connected to the earth using conductive wire as shown in Fig. 3. If there is a malfunction in the device, short-circuit current to aid the earth pass through the wire aid. Hence protect the system from damage.

\section{IMPORTANCE OR PURPOSE OF EARTHING}

Protect workers who are regularly exposed to electrical equipment that can shock them.

In the event of a single-phase earth fault, keep the device voltage constant in the healthy phase.

A good ground path that has a low impedance value ensures that electrical path faults are eliminated quickly. If defects in the system remain for a long time, they can pose a serious threat to the stability of the system.

Many modern electronic devices produce a form of "electrical noise" that can damage the device and reduce its efficiency, unless the device is grounded. Surge protectors work best with proper grounding.

Defective electrical equipment often leaks electricity, which has the ability to start a fire if not redirected safely.

IV. Classification of Earthing System

A low voltage distribution system (LV) It can be identified by its grounding system. These are defined using the five letters $\mathrm{T}$ (direct ground connection), $\mathrm{N}$ (neutral), $\mathrm{C}$ (combined), S (separate), and I (isolated from ground). The first letter indicates how the transformer neutral (power supply) is earthed, while the second letter indicates how the metalwork of an installation (chassis) is earthed. The third and fourth letters were respectively the functions of neutral conductors and protectors. The electrical network is illustrated in fig4.

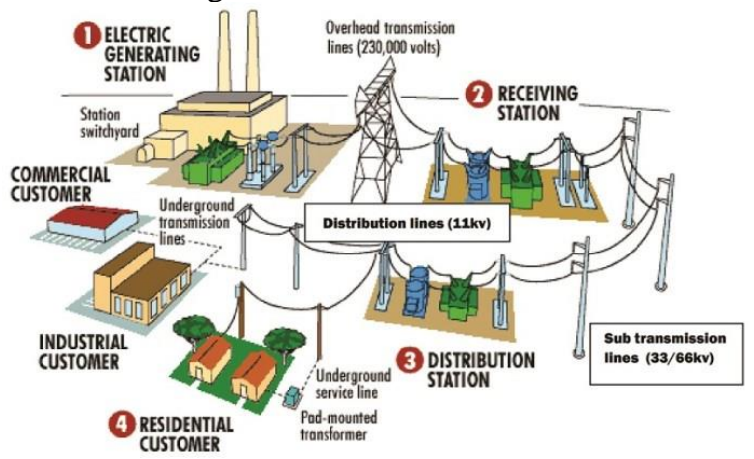

Figure 4: Power System Network
There are three possible configurations:

TN: Neutral transformer ground, connected to chassis neutral. The TN system consists of three subsystems: TN-C, TN-S and TN-C-S

TT: Neutral transformer and grounded chassis grounded.

IT: Grounded Neutral Transformer, Grounded Chassis.

TN Earthing System

In TN earthing systems, the power source (transformer neutral) is directly connected to the earth with one or more conductors and all the exposure conductive parts of an installation are connected to the neutral earth conductor or. Security. The three subsystems of the TN main system are described below, along with their salient features.

TN-C Earthing System

The TN-C system has the following characteristics:

Neutral and protective functions are combined in one conductor throughout the system. (PEN - Earth protection neutral).

The power source is directly connected to the earth and all exposed conductive parts of an installation are connected to the PEN conductor as shown in fig5.

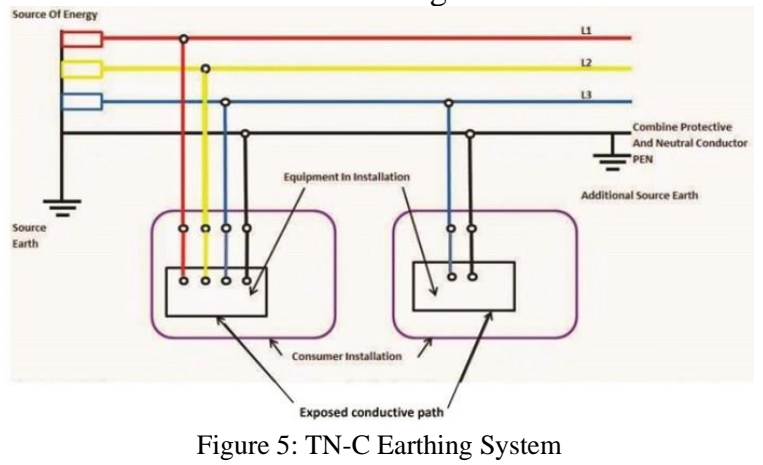

Advantages of TN-C Earthing System

The ground fault loop impedance of the TN-C earthing system is low.

It does not require a ground electrode on site.

It is economical.

Disadvantages of the TN-C Earthing System

The TNC earthing system is the least secure compared to other earthing systems.

The TN-C system is less effective for electromagnetic compatibility (EMC) problems.

A fault in the LV network may cause contact voltage from other BT customers.

TN-S Earthing System

The TN-S system has the following characteristics:

The TN-S system has neutral and protective conductors throughout the system.

The power source is directly connected to the earth. All exposed conductive parts of the installation are connected to a protective conductor (PE) through the main earthing terminal of the installation, as shown in fig6. 


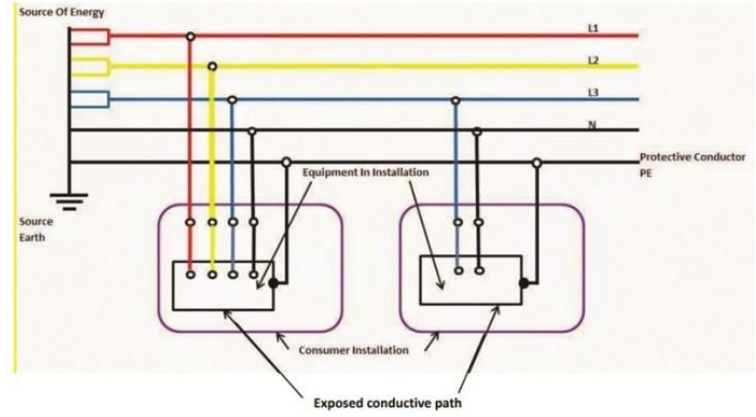

Figure 6: TN-S Earthing System

Advantages of TN-S Earthing System

The impedance of the ground fault circuit is low.

$\mathrm{TN}-\mathrm{S}$ is the safest system.

Electromagnetic interference is weak.

Does not require a ground electrode on site.

The TN-S grounding system could operate with a simple overcurrent protection.

Disadvantages of the TN-S Earthing System

Low power factor (high inductance of long cable).

Same additional capacity link is required.

In the event of an insulation fault, the short-circuit current is high and can damage the equipment or cause electromagnetic interference.

TN-C-S Earthing System

The TN-C-S earthing system has the following characteristics:

Neutral and protective functions are combined into a single conductor in a part of the TN-C-S system. The power supply is TN-C and the setup is TN-S as shown in Figure 7. Use of TN-S downstream of TN-C.

All exposed conductive parts of an installation are connected to the main earth terminal and the PEN conductor through the neutral terminal, these terminals being interconnected.

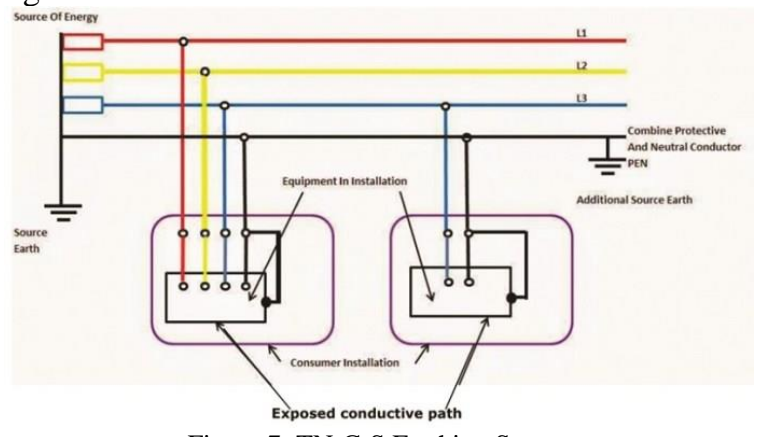

Figure 7: TN-C-S Earthing System

This type of distribution is also known as multiple protective earthing, and PEN conductors are called joint neutral and earth (CNE) conductors.

The PEN conductor of the power system is based on several points and may require a ground electrode in or near a consumer facility.

Advantages of TN-C-S Earthing System

Safe system

Less expensive.

Disadvantages of the TN-C-S Earthing System
Use TN-CS system, TN-S system (4-wire) should ever be in downstream TN-S system (5-wire), because the conductor due to any abrupt interruption of neutral on the upstream side The conductor will have safety in the downstream portion and hence the danger.

TT Earthing System

In this system, the power source has direct connection to the earth. All exposed conductive parts of the installation are also connected to a ground electrode that is electrically independent of the source ground, as shown in fig 8 .

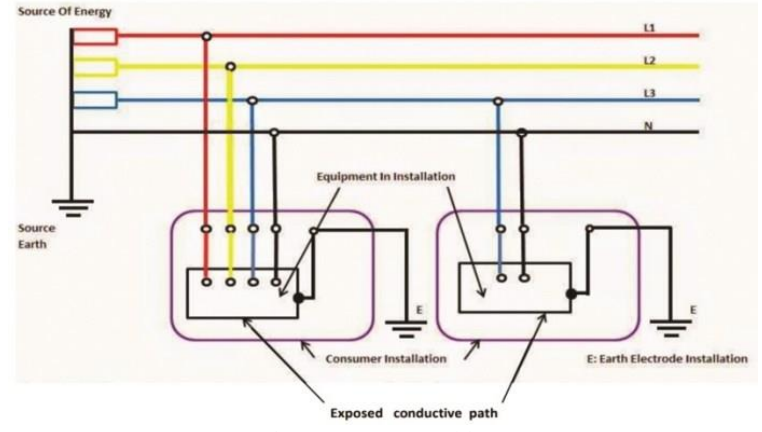

Figure 8: TT Earthing System

The fault loop impedance is higher, and unless the electrode impedance is indeed very low.

Advantages of TT System

There is no risk of failure and is suitable for premises where all AC supply circuits are protected by a residual current device (RCD).

Defects in LV and MV networks do not go to other customers on the BT network.

Simple Earthing of Installation and Simplest Installation.

Disadvantages of the TT Earthing System

Each customer must install and maintain their own ground electrode. Safety and protection depend on the customer, so total reliability is not guaranteed.

High overvoltage can occur between all living parts and between living parts and PE conductors.

Potential overvoltage constraint on insulation of installation equipment.

IT System Earthing

In this system, the power source is either connected to a high ground impedance (computer system with impedance ground) intentionally initiated from the ground, or isolated from the ground. All exposed conductive parts. An inductance is connected to the ground electrode, as shown in fig 9.

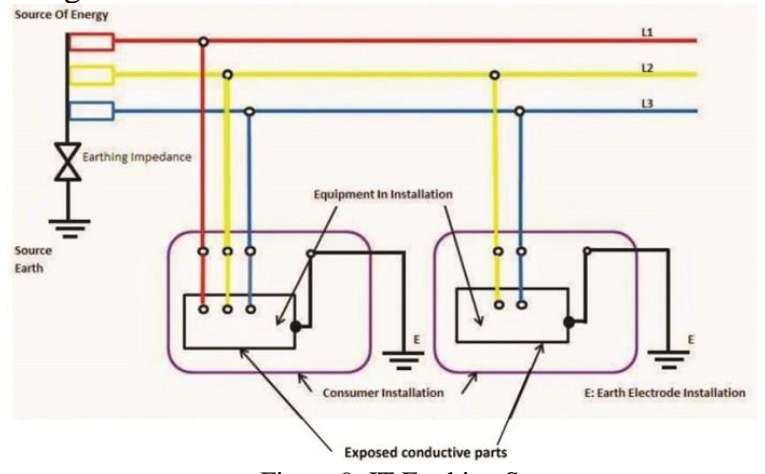

Figure 9: IT Earthing System 
The conductive parts, including the metal body of the installations, are connected to the earth via one or more local earth electrodes. These local electrodes have no direct connection to the source.

It is relevant to mention here that the single-phase TT system depicted in Figure 9 has not been used in India.

Advantages of IT system

The main advantages of a computer system are:

It improves energy availability: It is interesting for applications where electrical power loss may be a risk to people (for example in hospitals), or a financial risk (for some processes in industry).

It can also eliminate the risk of fire or explosion in the event of an insulation fault, as the faulty current is very low. This will increase the lifetime of electrical equipment, since the faulty current is low, it causes less stress on the equipment.

Finally, it is possible to perform preventive maintenance on IT installation. Thanks to permanent insulation monitoring equipment, we can detect a drop in insulation defects before they become insulation defects.

Disadvantages of IT system

This system experiences repeated arc patterns.

Insulation failure occurs during single phase earth faults.

Ground fault protection is difficult for grounded systems.

Voltage does not find its way to Earth due to lightning strikes.

Comparison of all Earthing Systems

Comparison of all grounding systems based on ground fault loop impedance, preferred RCD, requirement of onsite ground electrode, cost of PE conductors, etc. This was done as described in Table 1.

\begin{tabular}{|c|c|c|c|c|c|}
\hline Earthing System Conditions & TN-C & TN-S & TN.C-S & $\pi$ & IT \\
\hline Earth Fault Loop Impedance (EFL) & Low & Low & Low & High & Highest \\
\hline RCD Preference & No & Optional & Optional & Yes & N.A. \\
\hline Need of Earth Electrode at Site & No & No & Optional & Yes & Yes \\
\hline PE Conductor Cost & Least & Highest & High & Low & Low \\
\hline Risk of Broken Neutral & Highest & High & High & No & No \\
\hline Safety & Least safe & Safest & Safe & Safe & Less safe \\
\hline Electromagnetic Interference & High & Low & Low & Least & Least \\
\hline Safety risks & $\begin{array}{l}\text { Broken } \\
\text { neutral }\end{array}$ & $\begin{array}{l}\text { Broken } \\
\text { Neutral }\end{array}$ & $\begin{array}{l}\text { Broken } \\
\text { neutral }\end{array}$ & $\begin{array}{c}\text { High loop } \\
\text { Impedance } \\
\text { (step voltages) }\end{array}$ & $\begin{array}{l}\text { Double fault, } \\
\text { over voltage }\end{array}$ \\
\hline
\end{tabular}

Brief of earthing system adopted world-wide

In India, LT supply is usually done through the TN-S system. Neutrals are placed in distribution transformers, neutral and earth work separately on overhead distribution lines or cables. Additional earth electrode wells are installed at the user's ends to reinforce the earth.

Most modern homes in Europe have a TN-C-S grounding system. Neutral and earth joint transformers are between the station and the service cut-off (fuse before the meter), all internal wiring using separate earth and neutral conductors.

In areas of the UK where underground electrical wiring is common, the TN-S system is common.

In Australia, New Zealand and Israel, the TN-C-S system is used. However, each customer must provide a separate ground connection through a dedicated ground electrode.

The TN-C-S earthing system is used in the United States and Canada, while France, Italy and Japan use the TT earthing system.
TT system suitable for rural areas due to cost.

From the above information, it can be concluded that, if the grounding is not done properly, it can cause many problems such as:

\section{CONCLUSION}

From the above information, it can be concluded that, if the grounding is not done properly, it can cause ma Improper grounding creates a higher capacity in the equipment that can damage the equipment and pose a threat to the safety of working personnel.

This can delay the removal of faults, resulting in insufficient current flow.

Fire hazards caused by electrical leakage are increasing rapidly.

It can reduce operational efficiency of the machine.

In addition, the choice of earthing system depends on the priority given to several aspects mentioned in Table 1 by the distribution company and the competent regulatory regulatory authority.

\section{REFRENCES:-}

[1] https://electricalnotes.wordpress.com/2012/01/21/types-ofneutral-earthing-in-power-distribution/

[2] https://www.ecmweb.com/content/article/20899890/elevenpractical-tips-for-grounding-substations

[3] Application Guide Power for Engineers

[4] By-K.RAJAMANI

[5] INDUSTRIAL ELECTRONICS AND CONTROL

[6] BY- S.K. BHATTACHARYA, S.CHETTERJEE 